\title{
Improved incentive pricing-based quasi-linear utility function of wireless networks
}

\author{
Fitri Maya Puspita ${ }^{1}$, Bella Juwita Rezky ${ }^{2}$, Arden Naser Yustian Simarmata ${ }^{3}$, Evi Yuliza ${ }^{4}$, \\ Yusuf Hartono 5 \\ ${ }^{1-4}$ Mathematics Department, Mathematics and Natural Sciences Faculty, Sriwijaya University, Indonesia \\ ${ }^{5}$ Mathematics Education Study Program, Education and Teacher Training Faculty, Sriwijaya University, Indonesia
}

\begin{tabular}{l}
\hline Article Info \\
\hline Article history: \\
Received Mar 5, 2020 \\
Revised Mar 4, 2021 \\
Accepted Mar 30, 2021 \\
\hline
\end{tabular}

Keywords:

Bundle pricing

Incentive pricing

Optimal value

QoS attribute

Quasi-linear

Wireless network

\begin{abstract}
The model of the incentive pricing scheme-based quasi-linear utility function in wireless network was designed. Previous research seldom focusses on user's satisfaction while using network. Therefore, the model is then attempted to be set up that is derived from the modification of bundling and models of reverse charging and maintain the quality of service to users by utilizing quasi-linear utility function. The pricing schemes then are applied to local data server traffic. The model used is known as mathematical programming problem that can be solved by LINGO 13.0 program as optimization tool to get the optimal solution. The optimal results show that the improved incentive pricing can achieve better solution compared to original reverse charging where the models will be obtained in flat fee, usage-based, and two-part tariff strategies for homogeneous consumers.
\end{abstract}

This is an open access article under the CC BY-SA license.

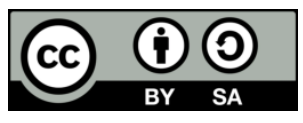

\section{Corresponding Author:}

Fitri Maya Puspita

Mathematics Department, Mathematics and Natural Sciences Faculty

Sriwijaya University

Raya Palembang-Prabumulih St., KM 32 Inderalaya Ogan Ilir, Sumatra Selatan 30662, Indonesia

Email: pipitmac140201@gmail.com

\section{INTRODUCTION}

One way for Internet service providers (ISPs) to enhance their quality of service is to perform the method of bundling and utility function [1], [2]. In wireless communication, one problem exists regarding with setting up the bundling or combining the service [3]. So, the best of services that are available can be taken that the maximum benefits. Model of focusing on bundling scheme maintains a utility function to support the quality of services (QoS) [4], [5] so the main goal to attract consumers to subscribe the services will improved fast and ISPs consider their level of satisfaction that can be maintained to engage users in dealing with the network [6], [7].

Network management is considered in critical state that every scheme regarding the pricing strategy should be maintained effectively. Internet pricing also should include the incentive for users maintaining the network [8]-[10]. Then, the requirement to have some mechanism to give user' incentive to upgrade the profit [11]-[16]. It means that users need some resources to enhance their satisfaction. Many pricing schemes are divided into whether the pricing scheme depends or not in the technical network that are leading to parameter selection to identify the price. The internet pricing scheme [6], [17], [18] has been developed tremendously nowadays. Many schemes that focus on users point of view [19]-[21] has emerged to persuade users in applying the wireless network. Reverse charging of internet is basically one of the scheme that focus on user while enhance ISP to obtain higher profit by conducting charging on using the network [22]. On the 
other side, bundling strategy that enhances users through promotion of some networks in one price, has been extensively used in wireless network [23], [24].

While some research focusing on some strategies to enhance users to obtain the benefit for ISP, very scarce research that focus on combination of incentive pricing, reverse charging strategy and bundling strategy in wireless network are discussed. In fact, the approach of those pricing scheme would be better for both users and ISP since they both get some satisfactions from the network. Therefore, it needs to model the improved incentive pricing based on internet usage on $3 \mathrm{G}$ and $4 \mathrm{G}$ networks that works on reverse charging scheme that allow user preferences. The bundling strategy allows users to differentiate the pricing scheme based on utility function chosen which is quasi-linear function as one of the well-known utility functions [25]-[28] to measure the level of satisfaction of the users. The models seek for ideal model that can both satisfy ISP for maintaining the networks and users applying the network.

\section{RESEARCH METHOD}

In this paper, the incentive scheme was set up by using a combination of optimization model of bundling pricing, quasi-linear utility function, the optimization problem of consumers, and improved reverse charging models with some numerical computations. The choice for setting the model is based on the ability of solver in LINGO 13.0 to solve the problem. The variables and parameters defined are described properly. Those include all variables and parameters involving in bundling strategies, utility function and improved reverse charging. The optimal solution is completed by using the LINGO 13.0. Numerical computations on this model are applied to the local data traffic server for examining the model designed. The main framework of designing the new model is presented in flowchart as Figure 1 showed.

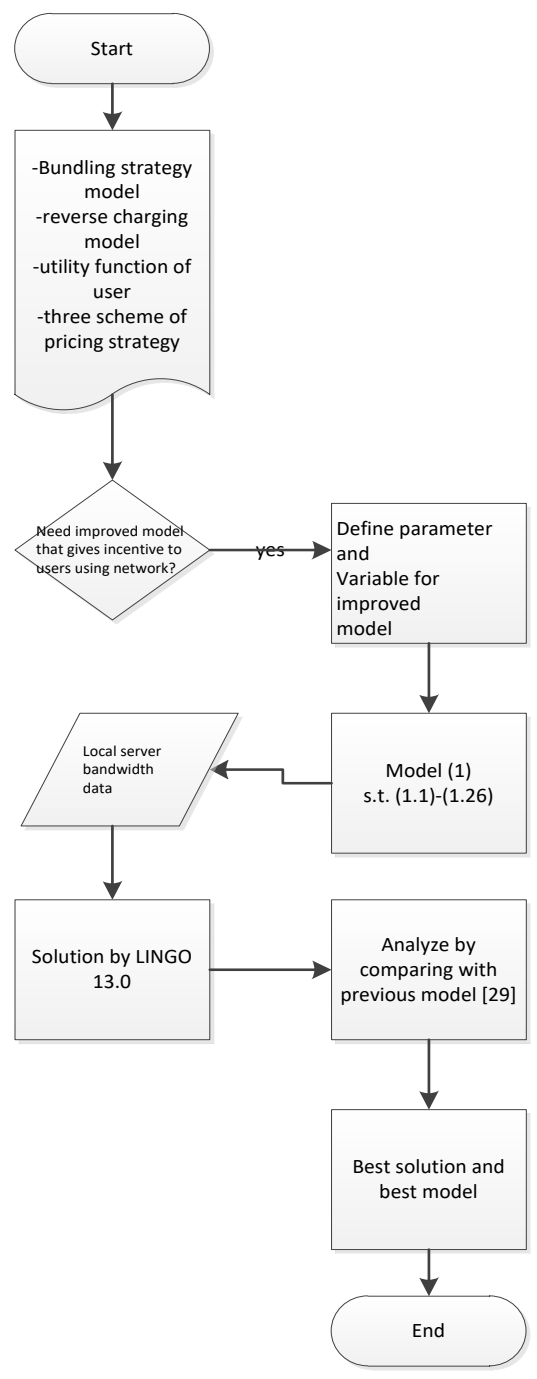

Figure 1. Flowchart of designing new model 


\section{RESULTS AND ANALYSIS}

All information needed are described in Tables 1 and 2. The value of parameter is presented in Tables 3 and 4. Parameters stated in Table 1 are basically regarding with bundling strategy, utility function of consumer, base price and quality premium that are maintained by ISP and reverse charging scheme parameters that allows ISP to charge back user that use the network.

Table 1. Parameters for each improved model

\begin{tabular}{cl}
\hline & Parameters for improved model \\
\hline$B_{j}$ & : Bundle cost for service $j$. \\
$R_{i j}$ & $:$ Marginal cost added in list. \\
$U_{i}\left(X_{i}, Y_{i}\right)$ & : Utility function $i$ in busy hour \\
$P_{X}$ & : Price per unit in busy hour. \\
$P_{Y}$ & : Price per unit in non busy hour. \\
$P$ & $:$ Paid cost by consumer. \\
$\alpha$ & $:$ Base price for maintanining class $j$. \\
$\beta$ & $:$ Quality premium \\
$C$ & $:$ Network capacity limitation \\
$P R_{i j}$ & $:$ Fee to connect needed \\
$m_{i}$ & $:$ Amount of minimum QoS require for service $i$ \\
$n_{i}$ & $:$ Amount of maximum QoS required for service $i$ \\
$d_{i j}$ & $:$ Capacity of service $i$ on network $j$ \\
$Q_{b i j}$ & $:$ Amount of value for QoS attribute \\
$f$ & $:$ Amount of minimum value for $a_{i j}$ \\
$h$ & $:$ Amount of minimum payload for $T_{l}$ \\
$k$ & $:$ Amounf of maximum payloads for $T_{l}$ \\
$g$ & $:$ Amount of maximum value for $a_{i j}$ \\
\hline
\end{tabular}

Table 2 states the decision variables to be determined that consist of decision of user to join the network or otherwise, benefit for user, cost change in reverse charging scheme and consumer consumption of the network. For Table 3, the values are set up by condition in the network on the data traffic from local server. Lastly, Table 4 describes the value set up for homogeneous users. Therefore, the improved incentive models attempt to have satisfaction of homogeneous users in network while enable ISP to gain their profit. Then, based on parameters and variables set up, the design of new improved model of incentive pricing is as (1).

Table 2. Decision variables for each improved model

\begin{tabular}{|c|c|}
\hline \multicolumn{2}{|r|}{ The decision variable for the improved model } \\
\hline & selecting bundle in service $j$ \\
\hline$X_{i j}$ & $:\{0$, not selecting bundle in service $j$ \\
\hline$Y$ & ISP sells bundle of services $j$ \\
\hline $1_{j}$ & $:\{0, \quad$ ISP does not sell bundle of services $j$ \\
\hline$S_{i}$ & : Amount of advantage for $-i$ consumer \\
\hline $\bar{X}_{l}$ & $\begin{array}{l}\text { : Amount of minimum consumption level } i \text { on the busy } \\
\text { hour. }\end{array}$ \\
\hline $\bar{Y}_{l}$ & $\begin{array}{l}\text { : Amount of maximum consumption level } i \text { on non } \\
\text { busy hour. }\end{array}$ \\
\hline$Z_{i}$ & $:\left\{\begin{array}{l}1, \quad \text { joining the scheme } \\
0, \text { no joining the scheme }\end{array}\right.$ \\
\hline$P Q_{i j}$ & : Amount of change in cost for change in QoS (IDR) \\
\hline$P B_{i j}$ & : Primary cost for a connection with user $i$ and class $j$ \\
\hline$a_{i j}$ & : Linearity cost factor in user $i$ and class $j$ \\
\hline$I_{i}$ & $\begin{array}{l}\text { : The base price of the minimum required for } \\
\text { service } i\end{array}$ \\
\hline$T_{l}$ & : Traffic load \\
\hline$L x$ & : Elasticity Factor \\
\hline$x$ & : Number of increase or decrease in QoS value \\
\hline$B$ & : The specified linear parameter \\
\hline
\end{tabular}

Table 3. Parameter values for improved models

\begin{tabular}{ll}
\hline \multicolumn{1}{c}{ Parameter } & \multicolumn{1}{c}{ Value } \\
\hline Cost of connecting user 1 class 1 $\left(P R_{11}\right)$ & 0.5 \\
Cost of connecting user 1 class 2 $\left(P R_{12}\right)$ & 0.6 \\
The cost of connecting users 2 class 1 & 0.4 \\
$\left(P R_{21}\right)$ & 0.7 \\
The cost of connecting users 2 class 2 & 1 \\
$\left(P R_{22}\right)$ & $0.05 \leq a_{11}$ \\
Linearity parameters $(a)$ & $\leq 0.15$ \\
Value limit $a_{11}$ & $0.06 \leq a_{12}$ \\
Value limit $a_{12}$ & $\leq 0.14$ \\
Value limit $a_{21}$ & $0.07 \leq a_{12}$ \\
Value limit $a_{22}$ & $\leq 0.13$ \\
Limitation of traffic load for $T_{l}$ & $0.08 \leq a_{12}$ \\
The base price for grade $1\left(\alpha_{1}\right)$ & $\leq 0.12$ \\
The base price for grade 2 $\left(\alpha_{2}\right)$ & $50 \leq T_{l} \leq 1000$ \\
Total bandwidth $(Q)$ & 0.1 \\
Minimum user bandwidth $1\left(V_{1}\right)$ & 0.2 \\
Minimum user bandwidth $2\left(V_{2}\right)$ & 102,400 \\
& 1 \\
\end{tabular}


Table 4. Parameter values for homogeneous consumers

\begin{tabular}{cccc}
\hline Parameter & Flat fee & $\begin{array}{c}\text { Value } \\
\text { Usage based }\end{array}$ & Two-Part tariff \\
\hline$V_{11}$ & 500 & 500 & 500 \\
$V_{12}$ & 800 & 800 & 800 \\
$V_{21}$ & 600 & 600 & 600 \\
$V_{22}$ & 900 & 900 & 900 \\
$M$ & 200 & 200 & 200 \\
$B_{1}$ & 300 & 300 & 300 \\
$B_{2}$ & 500 & 500 & 500 \\
$a$ & 3 & 3 & 3 \\
$b$ & 4 & 4 & 4 \\
$\bar{X}$ & 53.72 & 53.72 & 53.72 \\
$\bar{Y}$ & 59.57 & 59.57 & 59.57 \\
\hline
\end{tabular}

$\operatorname{Max} R=\sum_{i=1}^{2} \sum_{j=1}^{2}\left(P_{j}-B_{j}\right) X_{i j}-\sum_{j=1}^{2} M Y_{j}-\left(4 x+Y^{3}\right)+P_{X} X+P_{Y} Y+$ $P Z \sum_{i=1}^{2} \sum_{j=1}^{2}\left(\left(P R_{i j} \pm P Q_{i j}\right)+\left(\alpha+\beta I_{i}\right) P_{i j} X_{i j}\right)$

Subject to (1.1)-(1.26).

$S_{i} \geq\left(R_{i j}-P_{j}\right) Y_{j}$

$S_{i}=\sum_{j=1}^{2}\left(R_{i j}-P_{j}\right)$

$\left(R_{i j}-P_{j}\right) X_{i j} \geq 0$

$\sum_{j=1}^{2} X_{i j} \leq 1$

$X_{i j} \leq Y_{j}$

$S_{i} \geq 0$

$P_{i} \geq 0$

$X_{i j} \in\{0,1\}$

$Y_{i j} \in\{0,1\}$

$X_{i} \leq X_{i} Z_{i}$

$Y_{i} \leq Y_{i} Z_{i}$

$U(X, Y)-P_{X} X+P_{Y} Y+P Z \geq 0$

$Z_{i} \in\{0,1\}$

$I_{i} d_{i j} x_{i j} \leq a_{i} C$

$\sum_{i=1}^{2} \sum_{j=1}^{1} I_{i} d_{i j} x_{i j} \leq a_{i} C$

$\sum_{i=1}^{2} a_{i} \leq 1 \leq 1, a_{i} \in\{0,1\}$

$m i \leq I_{i} \leq 1, m_{i} \geq 0$

$0 \leq x_{i j} \leq n_{i}, x_{i j} \geq 0$

$P Q_{i j}=\left(1 \pm \frac{x}{Q_{b i j}}\right) P B_{i j} L x$

$P B_{i j}=a_{i j}\left(e-e^{-x B}\right) T_{l} / 100$ 


$$
\begin{aligned}
& L x=a\left(e-e^{-x B}\right) \\
& f \leq a_{i j} \leq g \\
& h \leq T_{l} \leq k \\
& 0 \leq x \leq 1 \\
& 0.8 \leq B \leq 1.07 \\
& a=1
\end{aligned}
$$

This model combines the optimization of bundling issues, which is to maximize $R=\sum_{i=1}^{2} \sum_{j=1}^{2}\left(P_{j}-B_{j}\right) X_{i j}-\sum_{j=1}^{2} M Y_{j}$, utility function based on Quasi-linear that is in form of $U(X, Y)=\left(4 x+Y^{3}\right)$, in which quasi-linear has combination of linear and nonlinear function. Then the optimization of consumer issues is to maximize $\theta=U(X, Y)-P_{X} X+P_{Y} Y+P Z$, and improved model of reverse charging of maximizing $R=\sum_{i=1}^{2} \sum_{j=1}^{2}\left(\left(P R_{i j} \pm P Q_{i j}\right)+\left(\alpha+\beta I_{i}\right) P_{i j} X_{i j}\right)$. The calculation of this model is divided into four cases which is based on whether to increase $P Q_{i j}$ or to increase $x$ or otherwise. Increase case means positive sign and decrease case means negative sign. Four cases are set up as follows:

For Case a: $P Q_{i j}$ and $x$ increase, then it will become (2).

$$
\operatorname{Max} R=\sum_{i=1}^{2}\left(P R_{i k}+P Q_{i k}\right)
$$

with $P Q_{i j}=\left(1+\frac{x}{Q_{b i j}}\right) P B_{i j} L x$.

For Case b: $P Q_{i j}$ increases and $x$ decreases, then it will become (3).

$$
\operatorname{Max} R=\sum_{i=1}^{2}\left(P R_{i k}+P Q_{i k}\right)
$$

with $P Q_{i j}=\left(1+\frac{x}{Q_{b i j}}\right) P B_{i j} L x$.

For Case c: $P Q_{i j}$ decreases and $x$ increases, then (4).

$$
\operatorname{Max} R=\sum_{i=1}^{2}\left(P R_{i 1}-P Q_{i 1}\right)
$$

with $P Q_{i j}=\left(1-\frac{x}{Q_{b i j}}\right) P B_{i j} L x$ and for Case d: $P Q_{i j}$ and $x$ decreases, then (5).

$$
\operatorname{Max} R=\sum_{i=1}^{2}\left(P R_{i k}-P Q_{i k}\right)
$$

with $P Q_{i j}=\left(1-\frac{x}{Q_{b i j}}\right) P B_{i j} L x$.

The pricing scheme widely known in network pricing scheme involves three schemes namely flat fee, which is based on subscription plan set up by ISP, usage based is based on network consumption per day, and two-part tariff scheme which has properties that users have to pay subscription fee and payment also be made based on consumption in those times. All those schemes are applied in homogeneous user which means that user only has consideration to apply the network or otherwise. In flat fee scheme, $P_{X}$ and $P_{Y}$ have to be 0 and $P>0$; usage-based scheme set the value of $P_{X}$ and $P_{Y}$ should greater than 0 and $P=0$ and in two-part tariff scheme, $P, P_{X}$ and $P_{Y}$ should be greater than 0 .

The (1.1)-(1.9) explain about bundling scheme in internet. If the consumer $i$ does not order the bundle, then $X_{i j}=0$, so that it will cause (1.2) and (1.3) to be 0 . If the consumer chooses to join the bundle provided, $X_{i j}=1$, so the value of $P_{j}$ must be calculated, which will not exceed the upper limit of the (1.7). As shown in dealing with user' satisfaction is presented in (1.10)-(1.13). The (1.13) are determined by consumer $i$, if consumer $i$ does not join the program then $Z_{i}$ is 0 so that (1.10) and (1.11) are 0 for their consumption level $\left(X_{i}\right.$ and $\left.Y_{i}\right)$ and total utility and cost are both zero. If consumer $i$ decides to join this program and chooses $Z_{i}=1$, then the consumer must decide on the optimal level of $X_{i}$ and $Y_{i}$ consumption, which cannot exceed the upper limit $\bar{X}_{i}$ and $\bar{Y}_{i}$. 
The (1.14) explains that the capacity required for services does not exceed the network capacity provided. The (1.15) explains that the capacity required for services cannot be greater than the total network capacity on the link $k$. The (1.16) explains that the amount of network capacity has a different allocation for each service located that lies between 0 and 1. The (1.17) states that the QoS level must be within the range of QoS levels that have been set for each service and the value of the QoS level is a positive integer. The (1.18) explains that the user implements a non-negative service and does not exceed the maximum number of service users determined by the service provider. The (1.19) explains the change in cost depending on the cost factor that involves the QoS bandwidth attribute, the base cost with service $i$ and link $k$, and the linearity factor. The (1.20) explains the basic costs for a connection with service $i$ and link $k$, which depend on the linear cost factor in service $i$ and link $k,\left(e-e^{-x B}\right)$ and the amount of traffic content. Furthermore, (1.21) explains the linearity factor which depends on the parameters $\alpha$ and $\left(e-e^{-x B}\right)$. The (1.22) describes the limitation of the linear factor value that is at the value set by the service provider. The (1.23) explains the restrictions on the allowable traffic load $T_{l}$ which the service provider also determines it. The (1.24) describes a number of increases or decreases in QoS values, which are set to 0 and 1 which indicate implicitly that if 0 means it is in the best effort condition and 1 is in perfect service condition. The value of $B$ on (1.25) is set to be between 0.8 and 1.07 because within this limit, the best service quality occurs. Value of $\alpha$ on (1.26) is a linear parameter that must be determined, with $\alpha$ parameter setting the basic level of prices.

Figure 2 displays the result for flat fee, usage based and two-part tariff schemes of homogeneous users solved by LINGO 13.0. All conditions of $P Q_{i j}$ and $x$ shows the same value. It means that user can choose any scheme based on their preferences and gain their incentive value based on their preferences while ISP enjoy their profit per user submitted. Again, the results show the same value for flat fee case, but for usage based, the time to complete the iteration takes 105 iterations. In real situation, it means that the operational cost to complete the job is in shorter time rather than other pricing schemes. Since two-part tariff strategy takes shorter time to complete the iteration, rather than for flat fee and usage-based schemes, then it is the best choice for users and ISP to be adopted since the profit for ISP is all the same values, but it needs only shorter time to complete the calculation. It can be seen as to save more resources on applying the network. It can be seen from Figure 2 (a) that for objective function value results in the same value. The solution with quasi linear-utility functions on homogeneous consumer showed that two-part tariff strategy has the best solution due to least number of iterations needed to complete the model as stated in Figure 2 (b). Previous model proposed by Puspita et al. [29] attempted to design model based on charging user that changing network from $3 \mathrm{G}$ to $4 \mathrm{G}$. The model makes the usefulness of price and QoS that change over the network. Unfortunately, the models are lack of the important features such as packet bundling strategy and user' choice on network. The solution is presented in Figure 3. As Figure 3 explained, the solutions are displayed in terms of objective function value, number of iterations, generated memory used, Steps taken and update interval using LINGO 13.0.

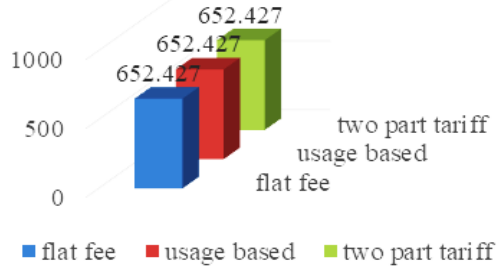

(a)

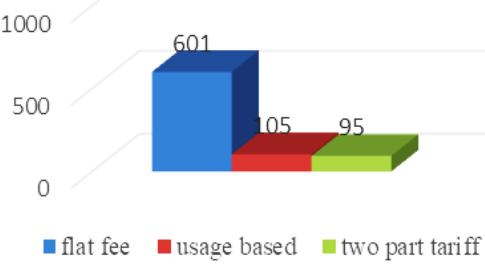

(b)

Figure 2. The result for flat fee: (a) objective function values and (b) number of iterations for improved incentive pricing

Therefore, to overcome such disadvantages, the improved model seek for the strategy that use the bundling strategy, on different pricing strategies that depends on price and QoS that change over the network as presented in Figure 4, that depicts the improved (1) subject to (1.1)-(1.26) that are compared with previous model proposed by Puspita et al. [29]. Figure 4 displays the comparison between model proposed by Puspita et al. [29] and our proposed model that differs in terms of the availability of three pricing schemes and bundle-pricing scheme How many incentives achieved by user's is by seeking the difference value from previous model [29] having the optimal incentive value of $107.47 / \mathrm{kpbs}$ and our improved model of 
$652.427 / \mathrm{kbps}$ that has the difference value of optimal revenue of $544.957 / \mathrm{kbps}$ that can be seen as the incentive gained by users.

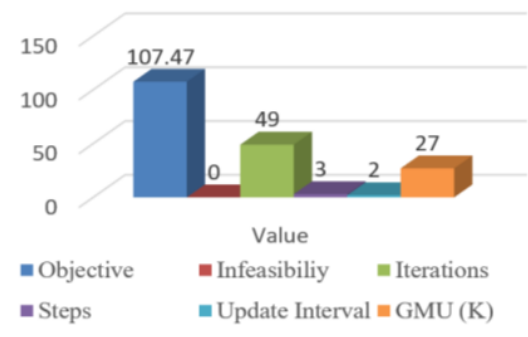

Figure 3. Solver status of model proposed by Puspita et al. [29]

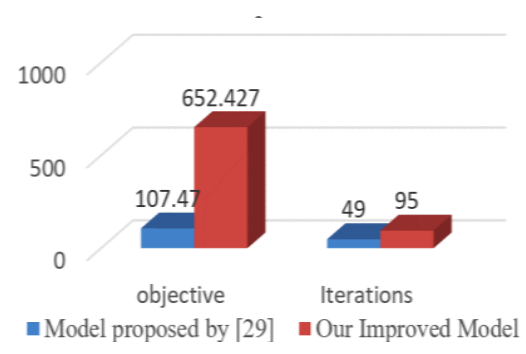

Figure 4. Comparisons between model proposed by Puspita et al. [29] and our improved model

\section{CONCLUSION}

Pricing incentive model of the internet has the best solution in homogeneous consumer by maintaining quasi-linear utility function if applying the two-part tariff schemes. It takes quite shorter time to finish the iterations rather than flat fee and usage based. It means that by both combine the subscription fee and based on usage, the incentive can be gained by user while ISPs obtain their goal to get higher revenue. However, of course, this research is more likely to be theoretical point of view rather than the practical terms. The idea for designing the model that ideally satisfies both ISP and users somehow can be designed in real condition. The involvement of heterogeneous users can be also considered to make very real condition of network. Therefore, for further research it is also possible to include heterogeneous users to have more complete objective of ISP to get higher profit.

\section{ACKNOWLEDGEMENTS}

The research leading to this article was supported finanancially by Indonesian Directorate of Higher Education through Fundamental Grant Scheme Year 2019.

\section{REFERENCES}

[1] W. Yang, H. L. Owen, and D. M. Blough, "Determining differentiated services network pricing through auctions," in Networking-ICN 2005, 4th International Conference on Networking April 2005 Proceedings, Part I, 2005, pp. 802-809, doi: 10.1007/978-3-540-31956-6_94.

[2] R. Sitepu, F. M. Puspita, A. N. Pratiwi, and I. P. Novyasti, "Utility function-based pricing strategies in maximizing the information service provider's revenue with marginal and monitoring costs," International Journal of Electrical and Computer Engineering, vol. 7, no. 2, pp. 877-887, 2017, doi: 10.11591/ijece.v7i2.pp877-887.

[3] F. M. Puspita, K. Seman, B. M. Taib and Z. Shafii, "Improved models of internet charging scheme of single bottleneck link in multi QoS networks," Journal of Applied Sciences, vol. 13, no. 4, pp. 572-579, 2013, doi: $10.3923 /$ jas.2013.572.579.

[4] W. Eltarjaman, M. Ashibani, and B. El-Jabu, "Towards optimized QoS based-charging model," Southern African Telecommunication Networks and Applications Conference(SATNAC 2007), 2007.

[5] L. Audah, Z. Sun, and H. Cruickshank, "QoS based admission control using multipath scheduler for IP over satellite networks," International Journal of Electrical and Computer Engineering, vol. 7, no. 6, pp. 2958-2969, 2017, doi: 10.11591/ijece.v7i6.pp2958-2969.

[6] F. M. Puspita, K. Seman, and B. M. Taib, "The improved models of internet pricing scheme of multi service multi link networks with various capacity links", Advanced Computer and Communication Engineering Technology, vol. 315, pp 851-862, 2015, doi: 10.1007/978-3-319-07674-4_80.

[7] K. Petrova, "ISPs-pricing Internet access," Beyond Boundaries. Proceedings of the 2003 GBATA International Conference, Budapest, Hungary, 2003, pp. 1042-1051.

[8] C. Gu, S. Zhang, and Y. Sun, "Pricing incentive mechanism based on multistages traffic classification methodology for QoS-enabled networks," Journal of Networks, vol. 6, no. 1, pp. 163-171, 2011, doi: 10.4304/jnw.6.1.163-171.

[9] T. Namerikawa, N. Okubo, R. Sato, Y. Okawa, and M. Ono, "Real-time pricing mechanism for electricity market with built-in incentive for participation," in IEEE Transactions on Smart Grid, vol. 6, no. 6, pp. 2714-2724, Nov. 2015, doi: 10.1109/TSG.2015.2447154.

[10] J. Lee and G.-L. Park, "Price effect analysis and pre-reseravtion scheme on electric vehicle charging networks," International Journal of Electrical and Computer Engineering (IJECE), vol. 9, no. 6, pp. 5586-5595, 2019, doi: 10.11591/ijece.v9i6.pp5586-5595. 
[11] A. I. Negash and D. S. Kirschen, "Compensation of demand response in competitive wholesale markets vs. retail incentives," 11th International Conference on the European Energy Market (EEM14), 2014, pp. 1-5, doi: 10.1109/EEM.2014.6861229.

[12] H. Wu, L. Liu, X. Zhang, and H. Ma, "Quality of video oriented pricing incentive for mobile video offloading, " IEEE INFOCOM 2016 - The 35th Annual IEEE International Conference on Computer Communications, 2016, pp. 1-9, doi: 10.1109/INFOCOM.2016.7524561.

[13] P. Loiseau, G. Schwartz, J. Musacchio, and S. Amin, "Incentive schemes for Internet congestion management: Raffles versus time-of-day pricing," 2011 49th Annual Allerton Conference on Communication, Control, and Computing (Allerton), 2011, pp. 103-110, doi: 10.1109/Allerton.2011.6120156.

[14] P. Loiseau, G. Schwartz, J. Musacchio, S. Amin, and S. S. Sastry, "Incentive mechanisms for internet congestion management: Fixed-budget rebate versus time-of-day pricing," in IEEE/ACM Transactions on Networking, vol. 22, no. 2, pp. 647-661, April 2014, doi: 10.1109/TNET.2013.2270442.

[15] L. Wang, Y. Yang, and Y. Wang, "Do higher incentives lead to better performance? - An exploratory study on software crowdsourcing," 2019 ACM/IEEE International Symposium on Empirical Software Engineering and Measurement (ESEM), 2019, pp. 1-11, doi: 10.1109/ESEM.2019.8870175.

[16] Y. He, H. Li, X. Cheng, Y. Liu, C. Yang, and L. Sun, "A blockchain based truthful incentive mechanism for distributed P2P applications," IEEE Access, vol. 6, pp. 27324-27335, 2018, doi: 10.1109/ACCESS.2018.2821705.

[17] V. Choudhary, "Use of pricing schemes for differentiating information goods," Information Systems Research, vol. 21, no. 1, pp. 78-92, 2010, doi: 10.1287/isre.1080.0203.

[18] J. Hwang, D. Lee, and K. Lee, "Internet pricing and network neutrality: How internet pricing schemes affect the incentives of internet service providers," International Telecommunications Policy Review, vol. 18, no. 1, pp. 17-44, 2011.

[19] A. Belghith, S. Trabelsi, and B. Cousin, "Realistic per-category pricing schemes for LTE users," 2014 12th International Symposium on Modeling and Optimization in Mobile, Ad Hoc, and Wireless Networks (WiOpt), 2014, pp. 429-435, doi: 10.1109/WIOPT.2014.6850329.

[20] T. Roughgarden, "Designing networks for selfish users is hard," Proceedings 42nd IEEE Symposium on Foundations of Computer Science, 2001, pp. 472-481, doi: 10.1109/SFCS.2001.959923.

[21] P. Reichl, et al., "Towards a comprehensive framework for QOE and user behavior modelling," 2015 Seventh International Workshop on Quality of Multimedia Experience (QoMEX), 2015, pp. 1-6, doi: 10.1109/QoMEX.2015.714813.

[22] R. A. M. Sprenkels, R. Parhonyi, A. Pras, B. J. van Beijnum, and B. L. de Goede, "Reverse charging in the internet an architecture for a new accounting scheme for internet traffic," IEEE Workshop on IP-Oriented Operations\&Management (IPOM2000) Cracow. Cracow, 2000.

[23] D. Niyato, D. T. Hoang, N. C. Luong, P. Wang, D. I. Kim, and Z. Han, "Smart data pricing models for the internet of things: a bundling strategy approach," IEEE Network, vol. 30, no. 2, pp. 18-25, March-April 2016, doi: 10.1109/MNET.2016.7437020.

[24] J. C.-I Chuang and M. A. Sirbu, "Optimal bundling strategy for digital information goods: network delivery of articles and subscriptions," Information Economics and Policy, vol. 11, no. 2, pp. 147-176, 1999, doi: 10.1016/S0167-6245(99)00008-6.

[25] T. Harks and T. Poschwatta, "Priority pricing in utility fair networks," 13TH IEEE International Conference on Network Protocols (ICNP'05), 2005, pp. 10 pp.-320, doi: 10.1109/ICNP.2005.33.

[26] W.-H. Kuo and W. Liao, "Utility-based optimal resource allocation in wireless networks," GLOBECOM '05. IEEE Global Telecommunications Conference, 2005., 2005, p. 5, doi: 10.1109/GLOCOM.2005.1578425.

[27] R. Sitepu, F. M. Puspita and S. Apriliyani, "Utility function based-mixed integer nonlinear programming (MINLP) problem model of information service pricing schemes," 2017 International Conference on Data and Software Engineering (ICoDSE), 2017, pp. 1-6, doi: 10.1109/ICODSE.2017.8285892..

[28] R. J. La and V. Anantharam, "Utility-based rate control in the Internet for elastic traffic," IEEE/ACM Transactions on Networking, vol. 10, no. 2, pp. 272-286, April 2002, doi: 10.1109/90.993307.

[29] F. M. Puspita, D. R. Nur, A. L. Tanjung, J. Silaen, and W. Herlina, "Mathematical model of improved reverse charging of wireless internet pricing scheme in servicing multiple QoS," Journal of Engineering and Scientific Research, vol. 1, no. 2, pp. 89-93, 2019, doi: 10.23960/jesr.v1i2.30.

\section{BIOGRAPHIES OF AUTHORS}

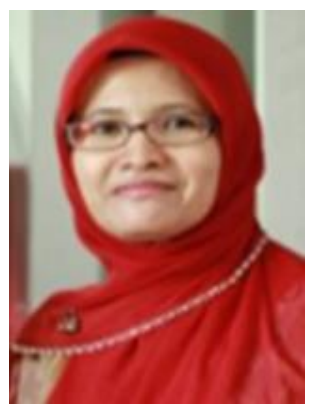

Fitri Maya Puspita received her S.Si degree in Mathematics from Sriwijaya University, South Sumatera, Indonesia in 1997. Then she received her M.Sc in Mathematics from Curtin University of Technology (CUT) Western Australia in 2004. She reveived his Ph.D in Science and Technology in 2015 from Universiti Sains Islam Malaysia. She has been a Mathematics Department member at Faculty mathematics and Natural Sciences Sriwijaya University South Sumatera Indonesia since 1998. Her research interests include optimization and its applications such as vehicle routing problems and QoS pricing and charging in third generation internet. 


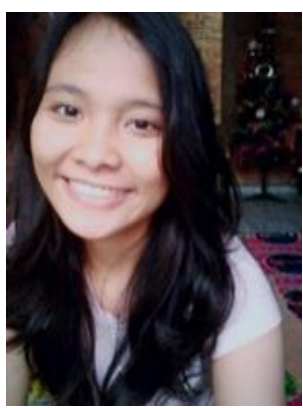

Bella Juwita Rezky received her S.Si degree in Mathematics from Sriwijaya University, South Sumatera, Indonesia in 2020. Her research interests are optimization focusing on incentive pricing problem of internet, bundling sheme of internet and utility function applied on networks

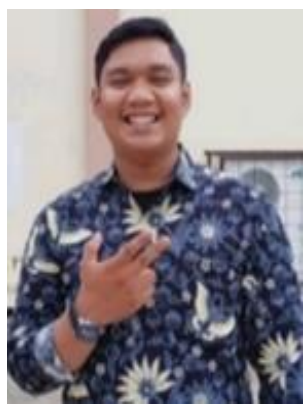

Arden Naser Simarmata reveiced his S.Si degree in Mathematics from Sriwijaya University, South Sumatera, Indonesia in 2020. His research interests are optimization focusing on incentive pricing problem of internet, bundling sheme of internet and utility function applied on networks and also reverse charging of the internet.

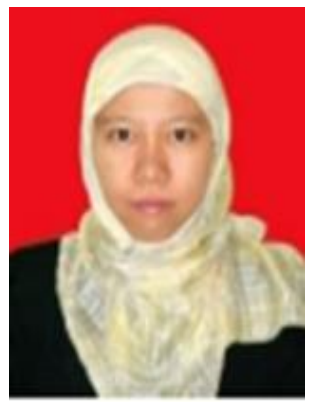

Evi Yuliza her S.Si degree in Mathematics from Sriwijaya University, South Sumatera, Indonesia in 2000. Then she received her M.Si in Mathematics from Gadjah Mada University in 2004. Her research interests include Algebra. She has been a Mathematics Department member at Faculty mathematics and Natural Sciences Sriwijaya University South Sumatera Indonesia since 2008 .

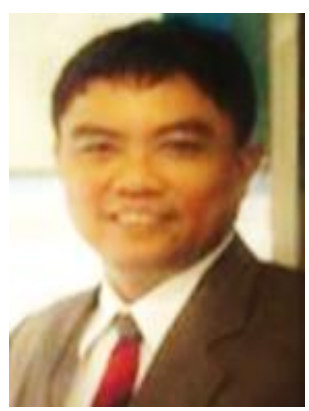

Yusuf Hartono received his Bachelor of Science in Mathematics Education from Sriwjaya University, Indonesia in 1988. Then he received his M.Sc in Math and Stats from Univ. of Missouri at Rolla, USA in 1993. He reveived his Ph.D in Mathematics in 2003 from Technische Universiteit Delft, Nederland. He has been a Mathematics Study Program member at Faculty of Education and Theacher Training Sriwijaya University South Sumatera Indonesia since 1990. His research interests include statistics and its application. 